\title{
LA PRODUCCIÓN CAMPESINA DE ALIMENTOS EN CONTEXTOS DE DISPUTA POR LOS RECURSOS EN LOS MUNICIPIOS DE Jala y Santiago Ixcuintla, Nayarit, México
}

\author{
Peasant Food Production in Contexts of Dispute for \\ Resources in the Municipalities of JAla and Santiago \\ IXCUINTLA, NAYARIT, MeXico
}

\author{
Jesús Antonio Madera Pacheco* \\ Dagoberto de Dios Hernández ${ }^{* *}$ \\ DOI: https://doi.org/10.31644/ED.V8.N1.2021.A05
}

\begin{abstract}
Resumen: Desde una perspectiva teórica centrada en una visión agroecológica, considerando que las familias campesinas son actores con capacidad de agencia, en este artículo se documentan las actuales dinámicas agroalimentarias que se ciernen sobre los territorios rurales de los municipios de Jala y Santiago Ixcuintla, Nayarit, y se muestra que las familias campesinas están reaccionando frente a ellas. Los movimientos de disputa en torno a la producción campesina de alimentos y, con ello, de defensa de las territorialidades construidas y resignificadas, no siempre se dan en la arena pública; sin embargo, se argumenta que las familias campesinas con, sin y a pesar de las intervenciones gubernamentales "de apoyo alimentario" resuelven su nutrimento utilizando estrategias múltiples que incluyen la producción —en diversos niveles de integración al mercado y autoconsumo-, la recolección, el trabajo asalariado y/o de apoyo mutuo, así como mediante redes de apoyo e intercambio tanto de alimentos como de otros recursos. Las familias campesinas en su día a día, y los colectivos en torno a ellos, resignifican las intervenciones externas y son capaces de construir acciones organizativas y socioproductivas.
\end{abstract}

Palabras clave: producción campesina, seguridad alimentaria, disputas, actores.

\footnotetext{
* Doctor en Agroecología, Sociología y Desarrollo Rural Sostenible, profesor investigador en el Área de Ciencias Sociales y Humanidades de la Universidad Autónoma de Nayarit, México, donde actualmente coordina el programa de Doctorado en Ciencias Sociales. ORCiD: http://orcid.org/0000-0001-5801-2686 Correo-e: jmadera@uan.edu.mx.

** Doctor en Desarrollo Rural, investigador miembro del cuerpo académico Actores Sociales y Desarrollo Comunitario, de la Universidad Autónoma de Nayarit, México. ORCiD: https://orcid.org/0000-0001-7252-3140 Correo-e: dagobertodediosh@gmail.com.
}

Fecha de recepción: 19/06/2020. Fecha de aceptación: 08/12/2020. Fecha de publicación: 30/01/2021.

\section{(cc) BY-NC-ND}

EntreDiversidades. Revista de Ciencias Sociales y Humanidades, vol. 8, núm. 1 (16), enero-junio 2021. Páginas: 119 - 140 ISSN-e: 2007-7610. https://doi.org/10.31644/ED.V8.N1.2021.A05 
Abstract: From a theoretical perspective focused on an agro ecological view, and considering peasant families as actors with agency, this paper documents the current agri-food dynamics that threaten the rural territories of the municipalities of Jala and Santiago Ixcuintla, Nayarit, and shows that peasant families are reacting against them. Dispute movements around peasant food production and, with it, the defense of constructed and re-signified territorialities, do not always occur in the public arena; however, the article argues, with, without and despite government "food support" interventions, families solve their diet need through multiple strategies, including production —at diverse levels of market integration and self-consumption-, gathering, wagelabor and/or mutual help, as well as support and exchange networks for food and other resources. Peasant families in their everyday activities, and organized groups around them, redefine external interventions and are capable of building organized and socio-productive actions.

Keywords: peasant agriculture, food security, disputes, actors.

\section{Introducción ${ }^{1}$}

En México, la adopción y profundización del modelo neoliberal "volcado al exterior" ha provocado un desmantelamiento premeditado de sectores y áreas que eran estratégicas para la vida económica y social. El país vive en una paradoja y contradicción, pues de ser un importante productor mundial de alimentos y centro de origen del maíz, se convirtió en un importador neto de este y de otros granos básicos, además de carne y leche. Las facilidades político-económicas que promovieron las inversiones extranjeras hacia territorio nacional como catalizadores de desarrollo, contrariamente han provocado graves problemas nacionales como pobreza, hambre, inseguridad, desposesión y degradación de los recursos naturales.

Como parte del territorio nacional, Nayarit no ha sido la excepción. Ahí, los municipios de Jala y Santiago Ixcuintla, otrora importantes en la producción de tabaco y maíz, entre otros cultivos, en los ańos recientes se han convertido en territorios asolados por la presencia sombría del capital transnacional proveniente de compañías como Monsanto y otras grandes semilleras mundiales, así como, bajo la sombra de estas, por grandes empresas productoras de hortalizas de exportación. El resultado es una competencia desleal para apropiarse y/o despojar a los cultivos locales de la tierra, agua y otros recursos naturales.

A la luz de ese contexto, vale cuestionarse: ¿cómo están siendo afectados los modos de vida y la producción campesina de alimentos para autoconsumo y comercio local? ¿Cómo están reaccionando y actuando los actores sociales en esos territorios rurales para enfrentar la amenaza del capital financiero? ¿Desde qué narrativas se ha abordado el problema de la soberanía y seguridad alimentaria en Nayarit? ¿Cuáles nuevas lentes teóricas pueden ayudar en el análisis y comprensión de este problema en esos territorios rurales?

\footnotetext{
${ }^{1}$ Este trabajo forma parte del proyecto de Ciencia Básica: A1-S-17116 "Desafíos de la Reconversión Productiva y sus contribuciones para la construcción de seguridad alimentaria en municipios productores de tabaco en Nayarit”, financiado por el Consejo Nacional de Ciencia y Tecnología (CONACYT) de México.
}

EntreDiversidades. Revista de Ciencias Sociales y Humanidades, vol. 8, núm. 1 (16), enero-junio 2021. Páginas: 119 - 140 ISSN-e: 2007-7610. https://doi.org/10.31644/ED.V8.N1.2021.A05 
Desde una perspectiva teórica centrada en una visión agroecológica y considerando a las familias campesinas como actores con capacidad de agencia —en términos de Long (2007) y Long y Ploeg (2011) — y de forma metodológica desde un enfoque etnográfico, este artículo muestra que las familias campesinas están reaccionando frente a las actuales dinámicas agroalimentarias que se ciernen sobre los territorios rurales de los municipios de Jala y Santiago Ixcuintla, Nayarit.

\section{Seguridad y soberanía alimentarias: aproximaciones desde Nayarit}

México pasa por una de las crisis más graves en materia de pobreza e inseguridad alimentaria. Según datos del Consejo Nacional de Evaluación de la Política de Desarrollo Social (CONEVAL), en 2018 un 52.4 millones de habitantes del país (el 41.9\% del total poblacional) vivían sumidos en la pobreza — de ellos, el 7.4\% en pobreza extrema—y solamente el 21.9\% de la población en México era considerada "no pobre y no vulnerable". Según la misma fuente, de 2008 a 2018 la pobreza en su dimensión por "carencia alimentaria" pasó de 24.3 a 25.5 millones de personas a nivel nacional, lo que representó para este último año el 20.4\% del total nacional (CONEVAL, 2020a).

La situación no es muy distinta para el caso de Nayarit. Según muestra CONEVAL, en 2018 el $34.8 \%$ de la población en Nayarit vivía en situación de pobreza y solamente el $24.4 \%$ de la población en la entidad era considerada "no pobre y no vulnerable"; para ese mismo ańo, la fuente indicaba que el $18.9 \%$ de la población en la entidad padecía carencia por acceso a la alimentación, proporción que, además, se ha incrementado en los últimos 10 años (CONEVAL, 2020b) (Tabla 1).

Tabla 1. Nayarit: población con carencias por acceso a la alimentación

\begin{tabular}{|c|c|c|}
\hline Año & Miles de personas & \% \\
\hline 2008 & 193.4 & 18.2 \\
\hline 2010 & 263.6 & 23.6 \\
\hline 2012 & 334.6 & 28.8 \\
\hline 2014 & 291.3 & 24.1 \\
\hline 2016 & 249.7 & 19.9 \\
\hline 2018 & 245.2 & 18.9 \\
\hline
\end{tabular}

Fuente: Elaboración a partir de CONEVAL, 2020b.

No obstante, parece que los esfuerzos, a través de la intervención gubernamental y la cantidad de recursos económicos destinados para atender el problema, no han sabido concretarse en su implementación (Crocker, et al., 2004; De Haro, et al., 2016; De Dios y Madera, 2019), pues muchas veces se incorporan alimentos culturalmente ajenos y descontextualizados, otras, directa o indirectamente, desincentivan la producción local y/o de autoconsumo. Son fenómenos complejos que requieren de aproximaciones también complejas e interdisciplinares; en este 
sentido, desde 2010, el grupo de investigación en torno al Cuerpo Académico Actores Sociales y Desarrollo Comunitario, de la Universidad Autónoma de Nayarit, ha realizado trabajo constante para el diagnóstico y acompańamiento de algunos procesos en torno a la seguridad y soberanía alimentaria bajo el cobijo de un enfoque agroecológico y de diálogo de saberes.

Aunado a lo anterior, vale destacar las mediciones realizadas para los municipios de Nayarit en torno a la Inseguridad Alimentaria (De Haro, et al., 2016) y Vulnerabilidad Alimentaria (De Haro y Marceleńo, 2019)²; en ambos casos, apoyándose en la versión armonizada para México de la Escala Latinoamericana y Caribeña de Seguridad Alimentaria (ELCSA).

Los resultados muestran que la seguridad alimentaria en los hogares de Nayarit, México, según la experiencia, para el año 2013 fue de 23.8\% y la inseguridad alimentaria (IA) de 76.2\% (De Haro, et al., 2016: 424) [...] la situación de inseguridad alimentaria se concentra en hogares con mayor número de menores de cinco años, mayor número de mayores de 64 años, mayor número de integrantes, jefatura femenina y menor escolaridad del (la) jefe(a) de familia (De Haro, et al., 2016: 424-425).

Los resultados de estas estimaciones [índice de vulnerabilidad alimentaria] muestran que los factores que más contribuyen a la vulnerabilidad alimentaria son la inseguridad alimentaria, la mortalidad infantil y los hogares con jefatura femenina (De Haro y Marceleño, 2019: 16).

De igual modo, sobresale la propuesta para entender seguridad y soberanía alimentarias como categorías complementarias, "bajo el supuesto de que en la vida cotidiana de los actores [ambas] están presentes en diversos momentos y formas" (Rivera y Garrafa, 2019: 98); de ahí la importancia, además de propuestas y programas integrales con pertinencia intercultural (Crocker, et al., 2004).

Para el caso de estudio [municipio de Ruiz, Nayarit] las estrategias de seguridad y soberanía alimentaria implican concepciones, conocimiento, prácticas y redes que les permita asegurar el alimento suficiente de su familia, pero también un nivel de autonomía para producir de acuerdo a una cultura propia que responde a qué, cuándo y cómo comer. Es decir, la visión del mundo campesino puesta en acción (Rivera y Garrafa, 2019: 98).

Rivera y Garrafa (2019) dan cuenta que los sectores de población más vulnerables son los de mayor edad — que muchas veces, además, viven solos—, así como las comunidades más alejadas de las zonas urbanas, donde las opciones de alimentos se reducen a los cultivados ahí y los pocos que llegan de fuera mediante Diconsa ${ }^{3}$ o con vendedores ambulantes en contadas ocasiones.

Por su parte, De Dios y Madera (2019) reflexionan acerca de las posibilidades que una intervención gubernamental, al menos en el discurso, podría tener sobre la seguridad alimentaria en el estado de Nayarit, particularmente con las familias productoras de tabaco. Sin embargo, a

\footnotetext{
${ }^{2}$ Encuentran que el " $40 \%$ de los municipios de Nayarit tienen un alto o muy alto Índice de Vulnerabilidad Alimentaria, 15\% tienen un índice medio y 35\% tienen un índice bajo o muy bajo” (De Haro y Marceleño, 2019: 11).

${ }^{3}$ Diconsa es una empresa de carácter estatal que busca "contribuir a la superación de la pobreza alimentaria, mediante el abasto de productos básicos y complementarios a localidades rurales de alta y muy alta marginación” (Presidencia de la República EPN, 2013).
}

EntreDiversidades. Revista de Ciencias Sociales y Humanidades, vol. 8, núm. 1 (16), enero-junio 2021. Páginas: 119 - 140 ISSN-e: 2007-7610. https://doi.org/10.31644/ED.V8.N1.2021.A05 
pesar de dichas posibilidades, los autores documentan la falacia del programa de Reconversión Productiva del Tabaco (RPT) hacia cultivos económica y socialmente más viables. También plantean la urgente necesidad de reconducir las acciones de gobierno hacia políticas que garanticen la producción de los alimentos que permitan construir una soberanía alimentaria para el país y para las familias productoras.

En un estudio con población wixaritari ${ }^{4}$ se documentó problemas de desnutrición alta, especialmente en la niñez menor a 12 años de edad, además de que "no se encontró una diferencia estadísticamente significativa entre los niños que reciben apoyo alimentario externo y los niños que no lo recibieron" (Crocker, et al., 2004: 692) ${ }^{5}$; de ahí la propuesta que estos autores hacen de recuperar las culturas alimentarias; culturas alimentarias, así, en plural, y situadas, entendiendo que para cada cultura los alimentos tienen sentidos diferenciados, tanto en sentido biológico como espiritual e identitario.

Es decir, reconocer las formas en que las y los actores locales —incluso los más vulnerables(Long, 2007; Long y Ploeg, 2011) con, sin y a pesar de las intervenciones gubernamentales "de apoyo alimentario" resuelven su alimentación, mediante estrategias múltiples como la producción (en diversos niveles de integración al mercado y autoconsumo), la recolección, los trabajos asalariados y/o de apoyo mutuo, así como redes de apoyo e intercambio tanto de alimentos como de otros recursos. En su día a día, resignifican las intervenciones externas y son capaces de construir acciones organizativas y socioproductivas.

\section{Metodología y contextos}

El presente artículo es resultado de una investigación que centra su mirar desde la agroecología y considera a las familias campesinas como actores con capacidad de agencia. Metodológicamente es una investigación etnográfica con apoyo de herramientas como la observación directa y participativa, diario de campo y entrevistas semiestructuradas y en profundidad que forman parte de un proceso permanente de idas y venidas al campo, pero que, para términos de este texto, se centra temporalmente en torno a los meses de abril 2018 y diciembre de 2019 como parte del trabajo doctoral de uno de los autores y de proyectos de investigación acción-participativa del otro.

Más allá de la cantidad de fragmentos de entrevistas semiestructuradas y en profundidad aquí citados, fueron realizadas aproximadamente 30 entrevistas con informantes clave, sobre todo con familias campesinas, pero también con actores político-gubernamentales, líderes de organizaciones de agricultores, comerciantes locales y otros. El número de entrevistas, junto al resto de herramientas e instrumentos, más que representar evidencias directas, ha procurado una proximidad con los actores y una inmersión en el territorio con el objetivo de identificar, tanto en

${ }^{4}$ Los wixaritari (plural, o bien, wixárika en singular) constituyen el grupo étnico predominante en el estado de Nayarit; sin embargo, su territorio se extiende también a parte de los estados de Jalisco, Durango, Zacatecas y San Luis Potosí.

${ }^{5}$ Se trata de una Investigación Acción Participativa (IAP) para "comprender la cosmovisión alimentario nutrimental" de la población acompañada, en la que "por períodos de ocho días cada dos meses, durante tres años, [estuvieron] acompañándoles en labores de producción, consumo y rituales que se realizan alrededor de los alimentos" (Crocker, et al., 2004: 694).

EntreDiversidades. Revista de Ciencias Sociales y Humanidades, vol. 8, núm. 1 (16), enero-junio 2021. Páginas: 119 - 140 ISSN-e: 2007-7610. https://doi.org/10.31644/ED.V8.N1.2021.A05 
el nivel discursivo como práctico, la trayectoria de eventos y acciones, observando, registrando, cuestionando y confrontando declaraciones en la cotidianidad de quienes viven y reconstruyen los territorios.

Como complemento metodológico y a modo de contrapuntear información, se realizó la revisión, sistematización y análisis hemerográfico de por lo menos 80 notas de periódicos locales, al menos durante los últimos 15 años (2005-2020), en las cuales se relatan eventualidades relacionadas con la producción de alimentos y disputas socioterritoriales en el estado de Nayarit.

Como casos de estudio, la mirada se centra en los municipios de Santiago Ixcuintla (en la costa norte) y Jala (en los valles del sur), ambos con características peculiares por su importancia agrícola, productores de tabaco y expulsores de mano de obra migrante. Para el caso del municipio de Jala, el trabajo de campo se concentró mayormente en las localidades de Jala, Coapan y Jomulco; mientras que en el municipio de Santiago Ixcuintla las observaciones de campo incluyeron un total de 13 localidades.

De acuerdo con estimaciones realizadas por De Haro y Marceleño (2019), el Índice de Vulnerabilidad Alimentaria para el municipio de Santiago Ixcuintla en 2015 fue de nivel "medio" y de "alto" para el municipio de Jala. Por su parte, De Haro, et al. (2016) calculan la inseguridad alimentaria moderada y severa por hogares a nivel municipal, diferenciando entre localidades urbanas y rurales; para el caso de Jala, se percibe que la padecen aproximadamente $38 \%$ en localidades rurales y $40 \%$ en localidades urbanas, mientras que para Santiago Ixcuintla es de un aproximado de 27\% y 19\%, respectivamente (De Haro, et al., 2016: 425).

Santiago Ixcuintla es el municipio con mayor superficie agrícola sembrada en el estado de Nayarit (SIAP, 2019a: 29); históricamente ha destacado por su importancia a escala estatal y nacional en la producción de tabaco, pero también por la producción pecuaria ${ }^{6}$ así como de frutales y granos básicos, entre ellos el maíz. ${ }^{7}$ En 2010, en este municipio se instaló un centro experimental de Monsanto con interés en la producción de maíz, mismo que ha adquirido más de 1800 hectáreas en las márgenes del río Santiago, sobre el cual, además, a la fecha operan tres grandes presas hidroeléctricas.

Por su parte, el municipio de Jala es un territorio donde prevalece la agricultura campesina y tradicionalmente de temporal, entre la que sobresale el cultivo de maíz raza Jala (conocido por los lugareńos como "maíz de húmedo"), que produce los maíces más grandes del mundo (en torno a los $60 \mathrm{~cm}$ de elote con grano); sin embargo, la superficie cultivada del maíz Jala se ha venido perdiendo y el tejido social de sus productores, desgastándose. Entre los factores que han generado este deterioro se encuentra la llegada de diferentes actores empresariales que han impulsado, por un lado, la sustitución de variedades criollas y otros cultivos de subsistencia por variedades comerciales de maíz ligadas a transnacionales; por otro, la creciente instalación de invernaderos para la producción empresarial de pepino y otras hortalizas de exportación.

\footnotetext{
${ }^{6}$ Según datos de Infografía Alimentaria para el estado de Nayarit, entre los 20 municipios que conforman a la entidad, Santiago Ixcuintla ocupa el quinto lugar en el estado en producción pecuaria, aportando el $5.7 \%$ del valor de la producción en el estado (SIAP, 2019a: 35).

${ }^{7}$ Entre los 20 municipios que conforman a la entidad, Santiago Ixcuintla ocupa el primer lugar en valor de la producción agrícola, pues aporta el 15.9\% del total en Nayarit (SIAP, 2019a: 30).
}

EntreDiversidades. Revista de Ciencias Sociales y Humanidades, vol. 8, núm. 1 (16), enero-junio 2021. Páginas: 119 - 140 ISSN-e: 2007-7610. https://doi.org/10.31644/ED.V8.N1.2021.A05 


\section{Dinámicas agroalimentarias en disputa}

Desde 1980, tras la substitución del modelo desarrollista por la adopción de uno de corte neoliberal, se sumió al país en una crisis permanente y desmantelamiento de diferentes áreas y sectores estratégicos, que en el ámbito agroalimentario le quitaron a México la capacidad de decisión en torno a su propia soberanía alimentaria (Universidad de Guadalajara, 2015). Para el caso de Nayarit, además de las disputas al interior del sector agropecuario — tipos de cultivo y su destino principal, entre otros - , a lo largo de las dos primeras décadas del siglo XXI las actividades terciarias y, entre ellas, específicamente el turismo, han recibido la atención e inversiones del Estado y del ámbito privado, disputando así terrenos y recursos a la agricultura y a la producción de alimentos.

En Nayarit las actividades agropecuarias le imprimen al estado una vocación natural por excelencia que destacan y son referente nacional en la producción de granos básicos —entre los que destaca particularmente el caso del arroz ${ }^{8}$ - hortalizas y frutales, así como en producción pesquera (SIAP, 2019b) (Tabla 2).

Tabla 2. Nayarit: productos destacados a nivel nacional

\begin{tabular}{|c|c|c|}
\hline Grupo & Producto & Lugar nacional \\
\hline Granos básicos & $\begin{array}{c}\text { Arroz } \\
\text { Frijol } \\
\text { Garbanzo }\end{array}$ & $\begin{array}{l}2^{\circ} \\
5^{\circ} \\
8^{\circ}\end{array}$ \\
\hline Hortalizas & $\begin{array}{c}\text { Berenjena } \\
\text { Tomate verde }\end{array}$ & $\begin{array}{l}4^{\circ} \\
8^{\circ}\end{array}$ \\
\hline Frutales & $\begin{array}{l}\text { Mango } \\
\text { Aguacate } \\
\text { Sandía } \\
\text { Jaca } \\
\text { Arándano } \\
\text { Piña } \\
\text { Plátano }\end{array}$ & $\begin{array}{c}2^{\circ} \\
4^{\circ} \\
6^{\circ} \\
1^{\mathrm{er}} \\
10^{\circ} \\
6^{\circ} \\
10^{\circ}\end{array}$ \\
\hline Otros cultivos & $\begin{array}{c}\text { Café cereza } \\
\text { Agave tequilero } \\
\text { Caña de azúcar } \\
\text { Coco } \\
\text { Sorgo } \\
\text { Tabaco }\end{array}$ & $\begin{array}{l}10^{\circ} \\
5^{\circ} \\
9^{\circ} \\
8^{\circ} \\
6^{\circ} \\
1^{\mathrm{er}}\end{array}$ \\
\hline Producción pesquera & $\begin{array}{c}\text { Camarón } \\
\text { Mojarra } \\
\text { Langosta } \\
\text { Atún } \\
\text { Pulpo }\end{array}$ & $\begin{array}{l}3^{\mathrm{er}} \\
5^{\circ} \\
5^{\circ} \\
7^{\circ} \\
9^{\circ}\end{array}$ \\
\hline
\end{tabular}

Fuente: elaboración propia a partir de SIAP, 2019b.

\footnotetext{
${ }^{8}$ Nayarit aporta el 26.8\% de la producción nacional, además, "la cosecha de Nayarit y Campeche, determinan la mayor disponibilidad de arroz en [el mes de] junio" (SIAP, 2019b: 34).

EntreDiversidades. Revista de Ciencias Sociales y Humanidades, vol. 8, núm. 1 (16), enero-junio 2021. Páginas: 119 - 140 ISSN-e: 2007-7610. https://doi.org/10.31644/ED.V8.N1.2021.A05
} 
Sin embargo, la producción agroalimentaria nayarita, en su conjunto, es más compleja y diversificada; muchos de sus cultivos locales no aparecen reflejados en las estadísticas y, sin embargo, están ahí en campo, dinamizando estrategias de vida e identidades campesinas y/o indígenas. La agricultura campesina, no siempre reconocida y contabilizada por las instancias gubernamentales, es sumamente importante en algunas comunidades nayaritas debido a su manejo de la diversidad de los agroecosistemas y, aunado a ello, al fortalecimiento de los procesos de soberanía alimentaria.

La producción campesina, compuesta por una variedad de cultivos (granos básicos, frutales y hortalizas), así como por las actividades pecuarias (domesticación y crianza de vacas, caballos, gallinas, puercos y colmenas), además de la pesca y la recolección de productos en "el monte" y/o caminos "sacacosechas", da forma a una economía circular de los recursos" que permite la reproducción material y simbólica, tanto en los predios agrícolas y el traspatio familiar, de la cultura alimentaria y de las identidades ligadas al territorio (Tabla 3).

\section{Tabla 3. Diversidad productiva de alimentos en los municipios de Jala y Santiago} Ixcuintla, Nayarit

\begin{tabular}{|c|c|c|c|c|c|c|}
\hline \multirow{2}{*}{ Actividad } & \multirow{2}{*}{ Tipo } & \multirow{2}{*}{ Aprovechamiento } & \multicolumn{4}{|c|}{ Usos } \\
\hline & & & $\mathbf{A}$ & $\mathrm{V}$ & I & $\mathrm{CA}$ \\
\hline \multirow{31}{*}{ Agricultura } & Maiz & Elote, maiz, olote, paja, hoja & $\mathrm{X}$ & $\mathrm{X}$ & $\mathrm{X}$ & $\mathrm{X}$ \\
\hline & Maiz Jala" & Elote, maiz, olote, paja, hoja & $\mathrm{X}$ & $\mathrm{X}$ & $\mathrm{X}$ & $\mathrm{X}$ \\
\hline & Frijol & Ejote, frijol, paja & $\mathrm{X}$ & $\mathrm{X}$ & $\mathrm{X}$ & $\mathrm{X}$ \\
\hline & Arroz palay ${ }^{*}$ & Grano & $\mathrm{X}$ & $\mathrm{X}$ & $\mathrm{X}$ & \\
\hline & Tomate & Fruto & $\mathrm{X}$ & $\mathrm{X}$ & $\mathrm{X}$ & \\
\hline & Tomate verde & Fruto & $\mathrm{X}$ & $\mathrm{X}$ & $\mathrm{X}$ & \\
\hline & Chile & Fruto & $\mathrm{X}$ & $\mathrm{X}$ & $\mathrm{X}$ & \\
\hline & Cacahuate & Fruto, paja & $\mathrm{X}$ & $\mathrm{X}$ & $\mathrm{X}$ & $\mathrm{X}$ \\
\hline & Calabaza & Fruto, planta & $\mathrm{X}$ & $\mathrm{X}$ & $\mathrm{X}$ & $\mathrm{X}$ \\
\hline & Garbanzo forrajero $^{* *}$ & Planta & & $\mathrm{X}$ & & $\mathrm{X}$ \\
\hline & Jamaica $^{* *}$ & Flor & $\mathrm{X}$ & $\mathrm{X}$ & $\mathrm{X}$ & \\
\hline & Sorgo & Grano, planta & & $\mathrm{X}$ & & $\mathrm{X}$ \\
\hline & Alfalfa verde ${ }^{* *}$ & Planta & & $\mathrm{X}$ & & $\mathrm{X}$ \\
\hline & Caña de azúcar & Azuicar, planta & $\mathrm{X}$ & $\mathrm{X}$ & & $\mathrm{X}$ \\
\hline & Agave tequilero ${ }^{* *}$ & Fruto & & $\mathrm{X}$ & & \\
\hline & Aguacate & Fruto, hojas & $\mathrm{X}$ & $\mathrm{X}$ & $\mathrm{X}$ & \\
\hline & Mango ${ }^{\circ}$ & Fruto & $\mathrm{X}$ & $\mathrm{X}$ & $\mathrm{X}$ & $\mathrm{X}$ \\
\hline & Limón & Fruto, hojas & $\mathrm{X}$ & $\mathrm{X}$ & $\mathrm{X}$ & \\
\hline & Plátano ${ }^{*}$ & Fruto, hojas, tallos & $\mathrm{X}$ & $\mathrm{X}$ & $\mathrm{X}$ & $\mathrm{X}$ \\
\hline & Papaya & Fruto & $\mathrm{X}$ & $\mathrm{X}$ & $\mathrm{X}$ & $\mathrm{X}$ \\
\hline & Café cereza ${ }^{*}$ & Fruto & $\mathrm{X}$ & $\mathrm{X}$ & $\mathrm{X}$ & \\
\hline & Piña ${ }^{*}$ & Fruto & $\mathrm{X}$ & $\mathrm{X}$ & $\mathrm{X}$ & \\
\hline & Guanábana & Fruto, hojas & $\mathrm{X}$ & $\mathrm{X}$ & $\mathrm{X}$ & \\
\hline & \begin{tabular}{|l|} 
Ciruela \\
\end{tabular} & Fruto & $\mathrm{X}$ & $\mathrm{X}$ & $\mathrm{X}$ & \\
\hline & Durazno $^{* *}$ & Fruto & $\mathrm{X}$ & $\mathrm{X}$ & $\mathrm{X}$ & \\
\hline & Guayaba $^{24}$ & Fruto, hojas & $\mathrm{X}$ & $\mathrm{X}$ & $\mathrm{X}$ & \\
\hline & Nopales & Hojas & $\mathrm{X}$ & $\mathrm{X}$ & $\mathrm{X}$ & \\
\hline & Pasto & Planta & & $\mathrm{X}$ & & $\mathrm{X}$ \\
\hline & Uva para vino ${ }^{4 *}$ & Fruto & & $\mathrm{X}$ & & \\
\hline & Berenjena ${ }^{*}$ & Fruto & & $\mathrm{X}$ & & \\
\hline & Ejote & Fruto & & $\mathrm{X}$ & & $\mathrm{X}$ \\
\hline
\end{tabular}

\footnotetext{
${ }^{9}$ Aunado a lo anterior, Nayarit también se ha vinculado históricamente a la producción agropecuaria nacional por sus actividades agroindustriales en cultivos otrora importantes como el tabaco; así como en procesos migratorios a través de la mano de obra especializada en la agricultura en diferentes regiones de Estados Unidos. Así, todo ello forma parte de las estrategias de vida y de reproducción social propias de las familias campesinas.
}

EntreDiversidades. Revista de Ciencias Sociales y Humanidades, vol. 8, núm. 1 (16), enero-junio 2021. Páginas: 119 - 140 ISSN-e: 2007-7610. https://doi.org/10.31644/ED.V8.N1.2021.A05 


\begin{tabular}{|c|c|c|c|c|c|c|}
\hline & Garbanzo grano ${ }^{*}$ & Grano & & $\mathrm{x}$ & & \\
\hline & Jicama* & Fruto, hojas & $\mathrm{x}$ & $\mathrm{x}$ & $\mathrm{x}$ & $\mathrm{x}$ \\
\hline & Melón & Fruto, planta & $\mathrm{X}$ & $\mathrm{x}$ & $\mathrm{x}$ & $\mathrm{X}$ \\
\hline & Melón amargo ${ }^{*}$ & Fruto & & $\mathrm{x}$ & & \\
\hline & Okra (angí o gombo) ${ }^{*}$ & Fruto & & $\mathrm{x}$ & & \\
\hline & Pepino & Fruto, planta & $\mathrm{x}$ & $\mathrm{X}$ & $\mathrm{x}$ & $\mathrm{x}$ \\
\hline & Sandia* & Fruto, planta & $\mathrm{x}$ & $\mathrm{x}$ & $\mathrm{x}$ & $\mathrm{x}$ \\
\hline & Ajonjoli" & Grano & & $\mathrm{x}$ & & \\
\hline & Semilla de soya ${ }^{*}$ & Fruto & & $\mathrm{X}$ & & \\
\hline & Coco fruta & Fruto & $\mathrm{x}$ & $\mathrm{x}$ & $\mathrm{x}$ & \\
\hline & Jaca (jackfruit) $^{*}$ & Fruto & $\mathrm{X}$ & $\mathrm{x}$ & $\mathrm{x}$ & \\
\hline & Litchi $^{*}$ & Fruto & & $\mathrm{x}$ & & \\
\hline & Nanche & Fruto & $\mathrm{X}$ & $\mathrm{X}$ & $\mathrm{X}$ & \\
\hline \multirow{9}{*}{ Pecuaria } & Vaca & Leche / Carne / Ahorro & $\mathrm{x}$ & $\mathrm{x}$ & $\mathrm{X}$ & \\
\hline & Caballo / Mula & Transporte / Yunta / Ahorro & $\mathrm{x}$ & $\mathrm{x}$ & $\mathrm{X}$ & \\
\hline & Burro & Transporte / Semental & & $\mathrm{x}$ & $\mathrm{x}$ & \\
\hline & Puerco & Carne / Ahorro & $\mathrm{x}$ & $\mathrm{x}$ & & \\
\hline & Gallina & Huevo / Carne / Ahorro & $\mathrm{X}$ & $\mathrm{x}$ & $\mathrm{x}$ & \\
\hline & Pato & Huevo & $\mathrm{x}$ & $\mathrm{x}$ & $\mathrm{x}$ & \\
\hline & Borrego & Carne / Ahorro & & $\mathrm{x}$ & & \\
\hline & Chivo & Carne / Ahorro & & $\mathrm{X}$ & & \\
\hline & Abejas & Miel & $\mathrm{X}$ & $\mathrm{X}$ & $\mathrm{x}$ & \\
\hline \multirow{6}{*}{$\begin{array}{l}\text { Recolección } \\
\text { y/o pesca }\end{array}$} & Guamúchil & Fruto, cáscara, madera & $\mathrm{x}$ & $\mathrm{x}$ & $\mathrm{x}$ & $\mathrm{X}$ \\
\hline & Huajillo / Huaje & Fruto & $\mathrm{x}$ & $\mathrm{x}$ & & $\mathrm{X}$ \\
\hline & Guayaba & Fruto & $\mathrm{x}$ & & $\mathrm{x}$ & \\
\hline & Pescado & & $\mathrm{x}$ & $\mathrm{x}$ & $\mathrm{x}$ & \\
\hline & Camarón & & $\mathrm{x}$ & $\mathrm{x}$ & $\mathrm{X}$ & \\
\hline & Ostión & & $\mathrm{X}$ & $\mathrm{X}$ & $\mathrm{X}$ & \\
\hline \multirow{24}{*}{$\begin{array}{c}\text { Traspatio / } \\
\text { Solar }\end{array}$} & Maiz & & $\mathrm{X}$ & & $\mathrm{X}$ & $\mathrm{X}$ \\
\hline & Chile & & $\mathrm{x}$ & $\mathrm{x}$ & $\mathrm{x}$ & \\
\hline & Rábano & & $\mathrm{x}$ & $\mathrm{x}$ & & $\mathrm{X}$ \\
\hline & Cebolla & & $\mathrm{x}$ & $\mathrm{x}$ & & $\mathrm{x}$ \\
\hline & Camote & & $\mathrm{x}$ & $\mathrm{x}$ & & $\mathrm{x}$ \\
\hline & \begin{tabular}{|l|} 
Calabaza \\
\end{tabular} & & $\mathrm{X}$ & $\mathrm{x}$ & $\mathrm{x}$ & $\mathrm{X}$ \\
\hline & Zanahoria & & $\mathrm{x}$ & $\mathrm{x}$ & & $\mathrm{X}$ \\
\hline & Jitomate & & $\mathrm{x}$ & $\mathrm{X}$ & $\mathrm{X}$ & $\mathrm{X}$ \\
\hline & Ejotes & & $\mathrm{X}$ & $\mathrm{X}$ & $\mathrm{X}$ & $\mathrm{X}$ \\
\hline & Pepino & & $\mathrm{x}$ & $\mathrm{x}$ & $\mathrm{x}$ & $\mathrm{x}$ \\
\hline & Cilantro & & $\mathrm{x}$ & $\mathrm{X}$ & $\mathrm{X}$ & $\mathrm{X}$ \\
\hline & Limón & Fruto, hojas & $\mathrm{X}$ & $\mathrm{x}$ & $\mathrm{X}$ & \\
\hline & Guayaba & Fruto, hojas & $\mathrm{X}$ & $\mathrm{x}$ & $\mathrm{x}$ & \\
\hline & Mango & Fruto, leña & $\mathrm{X}$ & $\mathrm{X}$ & $\mathrm{X}$ & $\mathrm{X}$ \\
\hline & Ciruela & Fruto & $\mathrm{X}$ & $\mathrm{x}$ & $\mathrm{x}$ & \\
\hline & Arrayán & Fruto & $\mathrm{X}$ & $\mathrm{x}$ & $\mathrm{x}$ & \\
\hline & Nanchi & Fruto & $\mathrm{X}$ & $\mathrm{x}$ & $\mathrm{x}$ & \\
\hline & Papaya & Fruto & $\mathrm{x}$ & $\mathrm{x}$ & $\mathrm{x}$ & \\
\hline & Plátano & Fruto, hojas, tallos & $\mathrm{X}$ & $\mathrm{X}$ & $\mathrm{x}$ & \\
\hline & Guanábana & Fruto, hojas & $\mathrm{x}$ & $\mathrm{X}$ & $\mathrm{X}$ & \\
\hline & \begin{tabular}{|l|} 
Aguacate \\
\end{tabular} & Fruto & $\mathrm{X}$ & $\mathrm{X}$ & $\mathrm{X}$ & \\
\hline & Coco fruta & Fruto & $\mathrm{X}$ & & $\mathrm{x}$ & \\
\hline & Jaca (jackfruit) & Fruto & $\mathrm{X}$ & & $\mathrm{X}$ & \\
\hline & Litchi & Fruto & $\mathrm{X}$ & & $\mathrm{X}$ & \\
\hline
\end{tabular}

Nota 1: *Durante la observación sólo se encontró en el municipio de Santiago Ixcuintla. **Durante la observación sólo se encontró en el municipio de Jala.

Nota 2: A.- Autoconsumo V.- Venta I.- Intercambio CA.- Consumo animal Nota 3: Se considera la producción de alimentos también para uso de animales.

Fuente: elaboración propia a partir de SIAP (2019a y 2019b) sobre cultivos e información directa de trabajo de campo.

EntreDiversidades. Revista de Ciencias Sociales y Humanidades, vol. 8, núm. 1 (16), enero-junio 2021. Páginas: 119 - 140 ISSN-e: 2007-7610. https://doi.org/10.31644/ED.V8.N1.2021.A05 


\section{La sombría alianza Estado-conglomerados agroindustriales en Nayarit}

$\mathrm{Al}$ menos durante las últimas tres administraciones gubernamentales en la entidad ${ }^{10}$ se ha colocado a Nayarit en una situación de desigualdad que es resultado, por un lado, de las disparidades regionales y concentración de la riqueza principalmente en las zonas Centro y Costa Sur del estado por el comercio y el turismo; pero, por otra parte, también debido a la falta de inversión gubernamental y el consecuente abandono de la infraestructura productiva en los sectores campesinos e indígenas — aunado a las crecientes presiones gubernamentales para revertir la mentalidad hacia una producción agroempresarial—, lo que ha incidido en una profundización de la crisis agropecuaria en Nayarit.

El Estado se ha decidido por promover y favorecer el establecimiento de nuevas empresas que aprovechen las condiciones agroclimáticas, hídricas, geográficas y otros recursos con potencial agropecuario, puesto que así la economía agrícola estatal — sobre todo el subsector de producción hortofrutícola - podría llegar, asume el propio Estado, a tener gran importancia, lo cual incidiría en la generación de empleo rural, modernización agrícola y la contribución de divisas, para colocar a la agricultura nayarita como una de las más relevantes. Cuenta de ello se da en los Planes Estatales de Desarrollo (PED), donde se plantea que la llegada de inversiones externas se podría materializar en megaproyectos e infraestructura agropecuaria conocidos como Corredores agroindustriales (PED 2005-2011), ciudades industriales y cadenas agroalimentarias (PED 2011-2017) y Agro parques (PED 2017-2021).

En ese contexto, la llegada y actual presencia de grandes empresas y conglomerados agroindustriales como Monsanto en el municipio de Santiago Ixcuintla, o de Divemex en Jala, no son obra de la casualidad. El vacío dejado premeditadamente por el Estado ha sido aprovechado por el capital privado. En 2010 Monsanto llegó para establecerse en la región agrícola más importante del estado, pues las instalaciones para su Centro Internacional de Mejoramiento de Maíz y Sorgo están en una zona que:

Se caracteriza por su alta productividad debido a la existencia de tierras niveladas donde hay bastante agua disponible como resultado de una amplia infraestructura de canales de riego y un microclima favorable, que permite que con la combinación de tecnología sean obtenidos rendimientos aproximados de 14 a 20 toneladas por hectárea de maíz (Entrevistado 2, 2014).

De acuerdo con uno de los actores entrevistados en ese municipio, Monsanto incrementó su presencia en la llamada margen izquierda del río Santiago, donde inicialmente comenzó por rentar tierras a cinco o diez años, entregando a las familias $\$ 10000.00$ por hectárea con el consentimiento de que estas pudieran ser niveladas y producir así semillas de "alta calidad"; inclusive, algunos de esos terrenos fueron posteriormente comprados o quitados a sus propietarios originales.

Junto con Monsanto otras semilleras mundiales como Down AgroSciences y Pioneer han invertido en la construcción de infraestructura para la elaboración de semillas híbridas de

${ }^{10}$ 2005-2011 con Ney M. González Sánchez, 2011-2017 con Roberto Sandoval Castañeda y 2017-2021 con Antonio Echevarría García.

EntreDiversidades. Revista de Ciencias Sociales y Humanidades, vol. 8, núm. 1 (16), enero-junio 2021. Páginas: 119 - 140 ISSN-e: 2007-7610. https://doi.org/10.31644/ED.V8.N1.2021.A05 
“alta calidad", según documentó Navarro (2018), ya que han logrado concentrar tierras por aproximadamente 1800 hectáreas en ambas márgenes del río Santiago.

Por su parte, el establecimiento de proyectos de agricultura protegida transformó las condiciones de la región Sur desde finales de 1990 y principios de 2000, de acuerdo con Sifuentes y Rivera (2013). Según estas autoras, una de las líneas de desarrollo diseñadas desde el Estado fue favorecer "la instalación de proyectos agroindustriales privados, promovidos por inversionistas extranjeros, que han optado por la adquisición de tierras para el desarrollo de procesos productivos altamente tecnificados" (Sifuentes y Rivera, 2013: 61).

En ese sentido, la presencia de invernaderos para la producción hortofrutícola de exportación forma parte del llamado Clúster Agroindustrial del Sur (NayaSur) anunciado en 2009 por la Secretaría de Desarrollo Económico de Nayarit (SEDECONAY) y la Secretaría de Agricultura, Ganadería, Pesca y Alimentación (SAGARPA). NayaSur contemplaba la instalación de 600 hectáreas de invernaderos por empresas productoras de tomates ${ }^{11}$, con una inversión de 1500 millones de pesos y la generación aproximadamente de nueve mil empleos (Ulloa, 2009).

Concretamente en Jala, en 2010 el entonces gobernador del estado anunció "la instalación de invernaderos en las primeras 25 hectáreas de un total de 900” (Núńez, 2010). De acuerdo con Nieves (2018), Nasa, de Sinaloa, fue la primera empresa en llegar al municipio para cultivar jitomate, sin embargo, en 2018 las instalaciones fueron adquiridas por Divemex para la producción de pimientos ${ }^{12}$.

Desde y/o a partir de la llegada de estos agentes externos se han instalado otras empresas que abarcan la producción de cultivos hortícolas destinados a mercados internacionales (Agroproductos San Carlos, por ejemplo), o bien, orientadas a esquemas de agricultura por contrato en granos básicos (Granissa); así como megaproyectos como Canal Centenario, que busca trasvasar el agua de los ríos nayaritas hacia zonas agroempresariales en los estados de Sinaloa y Sonora, o Proyecto Ceboruco con el fracking y la explotación de energía geotérmica. La sombría presencia de esos actores - la mayor de las veces aliados al Estado — ha producido en ambos territorios una serie de disputas y confrontaciones por la diversidad de recursos locales. Resultado de una revisión y análisis hemerográfico de los principales periódicos de circulación local, la Imagen 1 nos permite dar cuenta de dichas confrontaciones y reconstruirlas en una especie de línea del tiempo.

\footnotetext{
${ }^{11}$ Inicialmente las empresas participantes en el proyecto eran Agrícola Chaparral, Agroindustrias Cósala, Hidropónicos Especializados de Chihuahua, Empresarios Locales, Invernaderos Bonanza 2001 y Desert Glory Nayarit II.

${ }^{12}$ Se trata de una empresa que tiene su matriz en Culiacán, Sinaloa, pero también tiene sucursales en Etzatlán y Ahualulco, Jalisco, cuyas zonas, por cierto, son líderes nacionales en la producción de este vegetal (Nieves, 2018).
}

EntreDiversidades. Revista de Ciencias Sociales y Humanidades, vol. 8, núm. 1 (16), enero-junio 2021. Páginas: 119 - 140 ISSN-e: 2007-7610. https://doi.org/10.31644/ED.V8.N1.2021.A05 


\section{Imagen 1. Nayarit y municipios de estudio. Tipos de disputa por los recursos}

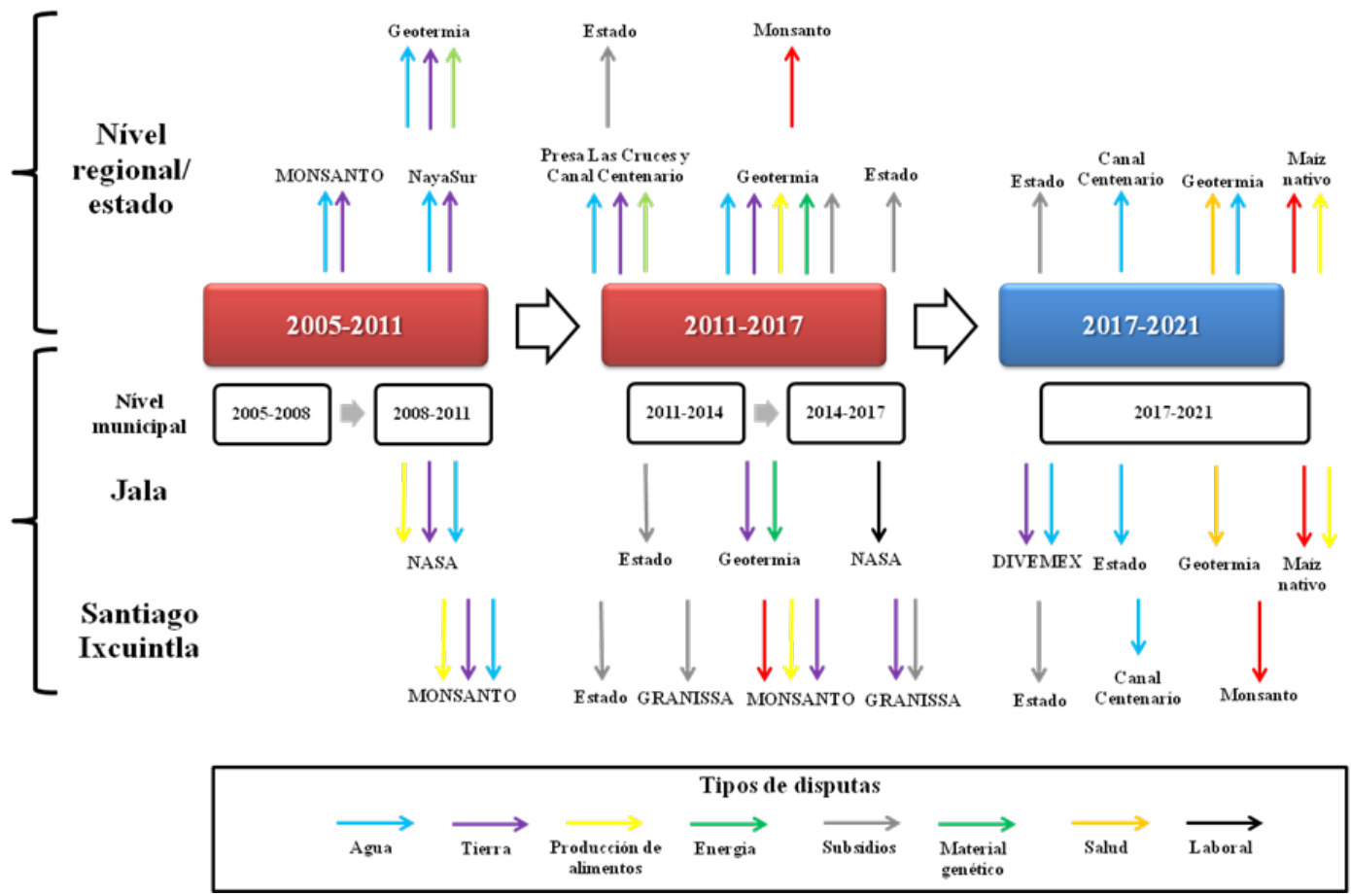

Fuente: elaboración propia a partir de revisión hemerográfica en Nayarit para el periodo 2005-2020.

Así, el Estado ha privilegiado en las actividades agrícolas aquellas de carácter empresarialproductivista, orientadas al comercio nacional e internacional, demeritando prácticas y cultivos campesinos que son importantes a nivel local por sus aportes al autoconsumo familiar, a la reproducción de saberes locales y al manejo de los agroecosistemas. Si bien desde el discurso gubernamental se dice reconocer la importancia y papel de las familias campesinas, sus organizaciones/sindicatos de representación y otros agentes rurales, en la práctica se ha relegado a los actores campesinos a un segundo término o lugar inferior de la jerarquía, desde donde apenas fungen como proveedores de materias primas, mano de obra barata y/o de conocimientos agrícolas.

\section{La pobreza alimentaria como ¿botín político?}

En México, históricamente los programas sociales e intervenciones gubernamentales para "atender" la pobreza y la alimentación se han vinculado a la visión y proyecto de nación imperante en cada sexenio. En ese sentido, también los múltiples programas alimentarios que han desfilado por el ámbito rural han atendido los mandamientos del régimen presidencial en turno y los lineamientos de organismos internacionales (Torres, et al., 2015). 
Al menos desde 1990, el extenso y cambiante repertorio de políticas alimentarias y programas sociales conforman un segundo periodo histórico en que los mecanismos de operación y características de focalización se han basado en criterios de eficiencia y racionalidad económica producto de las "recomendaciones" del Banco Mundial (BM) y/o el Fondo Monetario Internacional (FMI); entre los más reconocidos se pueden destacar el Programa de Desarrollo Humano Oportunidades (PDHO 2006-2012), posteriormente llamado Prospera (2012-2018), así como los Programas de Abasto Social de Leche (PASL) de Liconsa, de Apoyo Alimentario (PAL) y Abasto Rural de Diconsa (Sottoli, 2000, en Torres, et al., 2015). ${ }^{13}$

En Nayarit ha sido el Estado que ha utilizado diversos programas sociales de alcance estatal, aunque también algunos armonizados y/o en consonancia con los del ámbito federal, para intentar resolver los problemas de alimentación, salud y nutrición (Imagen 2). No obstante, más allá de las cifras oficiales que documentan avances en contra de la inseguridad alimentaria, el común denominador es que han sido manejados como catalizadores de los discursos de pobreza y hambre, utilizándolos con fines político-electorales o de promoción personal, por ejemplo, en 2012 el gobernador ${ }^{14}$ en turno bautizó la intervención estelar de su gobierno con el nombre de Programa Seguro Alimentario (PROSA).

En ese sentido, cada administración estatal en Nayarit ha tenido en su política social un programa estelar, como fue la Pensión Alimentaria para Jóvenes de la Tercera Edad y Mujeres embarazadas en el periodo 2005-2011, o en el actual (2017-2021) el programa llamado de Alimentación Básica Completa (ABC). Estos, como el PROSA, han consistido en la entrega de kits/cestas de productos alimentarios o una tarjeta recargable con puntos electrónicos para ser utilizados en la compra de alimentos en tiendas previamente instaladas y administradas por el Estado en los diferentes municipios.

\footnotetext{
${ }^{13}$ Los de primera generación, que abarcan los programas sociales desde los años 1960 hasta mediados de los 1990, se caracterizaron por cuantiosos recursos para subsidios generalizados de apoyo a la alimentación; están entre sus principales ejemplos el Programa de Inversiones Públicas para el Desarrollo (PIDER), el Sistema Alimentario Mexicano (SAM) y el Plan Nacional de Zonas Deprimidas y Grupos Marginados (COPLAMAR) (Sottoli, 2000 en Torres, et al. 2015: 56).

${ }^{14}$ El gobernador aludido es Roberto Sandoval Castañeda (2011-2017) de extracción priista. Era ampliamente conocido en Nayarit, aunque lo negara el gobierno, que la sigla PROSA se entendía como Programa Roberto Sandoval.
}

EntreDiversidades. Revista de Ciencias Sociales y Humanidades, vol. 8, núm. 1 (16), enero-junio 2021. Páginas: 119 - 140 ISSN-e: 2007-7610. https://doi.org/10.31644/ED.V8.N1.2021.A05 


\section{Imagen 2. Programas sociales con énfasis alimentario e incidencia en Nayarit, 2005-2021}

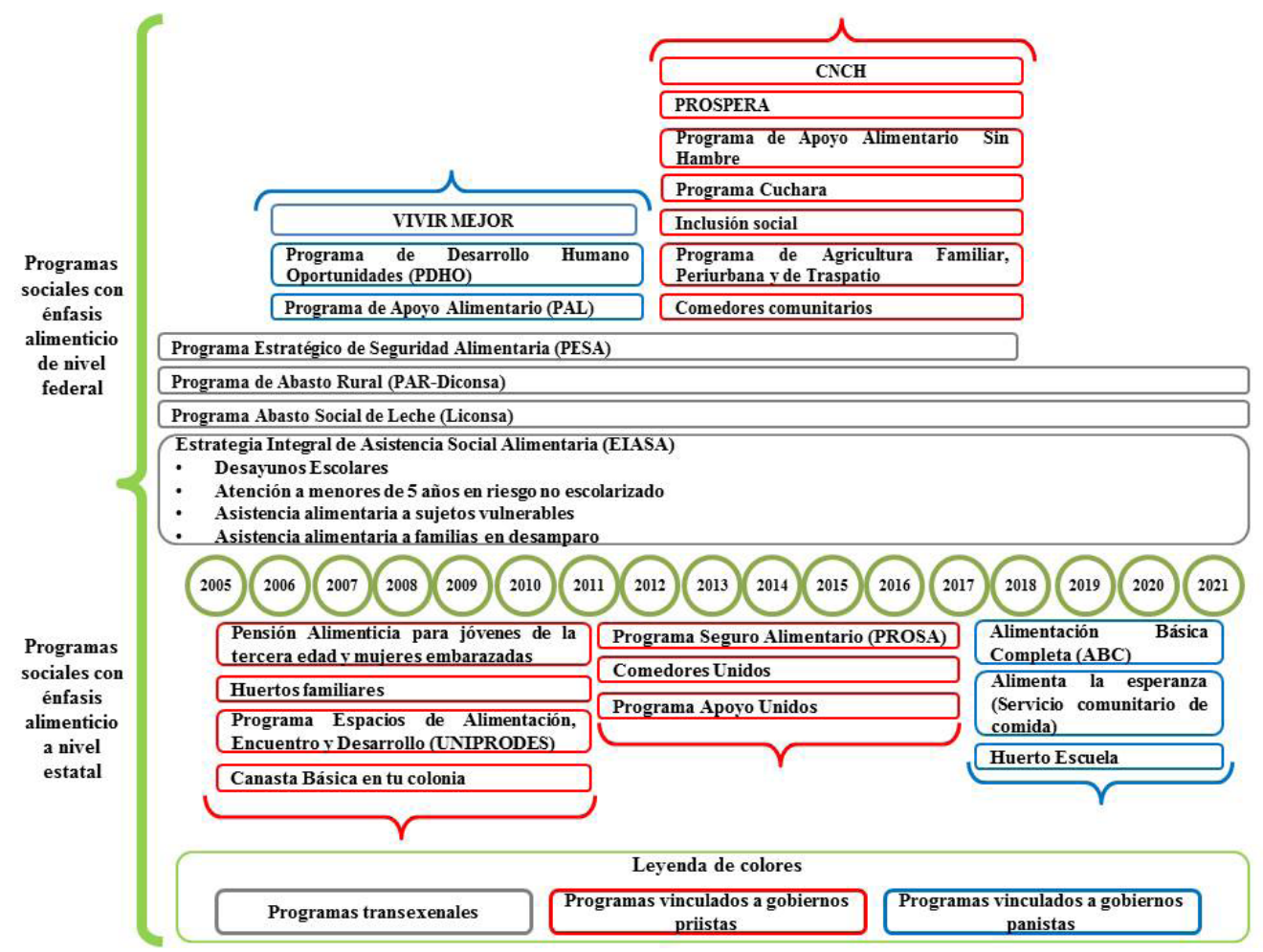

Fuente: elaboración propia a partir de Gobierno Constitucional del Estado de Nayarit (2005, 2011 y 2017) y revisión hemerográfica en Nayarit para el período 2005-2020.

A pesar de las acciones emprendidas por el Estado, pocos o escasos son los resultados aun cuando después de 25 años el gasto social se ha triplicado (La Jornada, 2017). ${ }^{15}$ Las respuestas a la ineficacia gubernamental pueden ser muchas. Por un lado, de acuerdo con las postulaciones de Souza y Belik (2012), la política de alimentación en México ha sido planeada con base en acciones fragmentadas o que intentan compensar los errores de inclusión de programas como Progresa/Oportunidades/Prospera. Asimismo, estos autores encuentran que:

[...] a pesar de la existencia de muchos programas para ampliar la oferta de alimentos en México, estos poseen un presupuesto inferior comparado con los programas de acceso a alimentos. Datos muestran que 43\% del presupuesto destinado al medio rural en México tiene como destino las transferencias monetarias [...]. Así, además de la fragmentación presente en la política de alimentación, ha existido una centralización presupuestal en favor de la dimensión de acceso a los alimentos frente a las dimensiones de disponibilidad, oferta y uso de los alimentos (Souza y Belik, 2012: 116-117). ${ }^{16}$

\footnotetext{
${ }^{15}$ De acuerdo con Fernández-Vega (2019), al menos de 2008 a 2018 se destinaron recursos públicos superiores a un billón de pesos para combate a la pobreza. En 2008, la asignación fue de 35 mil millones de pesos; para 2013 el monto aumentó a 95 mil millones y en 2018 fueron 106 mil millones los presupuestados para el Desarrollo Social.

${ }^{16}$ Traducción de los autores del original en portugués brasileńo: “[...] apesar da existência de muitos programas para

EntreDiversidades. Revista de Ciencias Sociales y Humanidades, vol. 8, núm. 1 (16), enero-junio 2021. Páginas: 119 - 140 ISSN-e: 2007-7610. https://doi.org/10.31644/ED.V8.N1.2021.A05
} 
Por otro lado, las intervenciones gubernamentales, lejos de recuperar los patrones alimentarios cultural y regionalmente situados, "no han estado exentas de una política sistemática de cambiar patrones alimentarios de las poblaciones rurales" (Torres, et al., 2015: 56), buscando acercarlos a los que provee la industria alimentaria de ultraprocesados con una aparente idea de "sociedad moderna". Por ejemplo, el caso del programa "desayunos escolares" implementado desde el ámbito federal, y con incidencia también en el estado de Nayarit, como parte de una estrategia "integral de asistencia social alimentaria", no considera aspectos socioculturales ni regionales de la alimentación y, por el contrario, se introducen "alimentos" que son ajenos a las poblaciones y tampoco se dinamizan las economías ni producción locales de alimentos.

En Nayarit, como en otros estados de México, los gobiernos en turno mediante los programas sociales y las intervenciones gubernamentales no buscan atender y resolver el problema de fondo que provoca la inseguridad alimentaria. El Estado establece una seguridad alimentaria neoliberal a través de la cual garantiza la disponibilidad de los alimentos vía importaciones (nunca por el fomento de la producción para autoconsumo y comercio local, por ejemplo) y transfiere recursos mediante políticas y programas sociales para que así sus clientes "pobres" tengan un ingreso asegurado para la compra de los mismos. No se busca atender la pobreza y el hambre, tampoco fomentar la producción local y campesina de alimentos que incidan directamente en la seguridad y soberanía alimentarias, sino garantizar el funcionamiento de la fábrica de pobres propiedad del Estado.

\section{Algunas reacciones desde lo local}

En la Tabla 4 se muestra una serie de lo que consideramos amenazas a la producción campesina de alimentos en los municipios de Santiago Ixcuintla y Jala en el estado de Nayarit, así como algunas de las reacciones frente a ellas por parte de actores locales. Como hemos visto en apartados anteriores, la realidad es compleja, la producción de alimentos en los municipios de estudio también lo es; una producción biodiversa que considera tanto alimentos para autoconsumo como otros orientados hacia el mercado y cuyos ingresos circulan en la economía y estrategias campesinas de vida. Incluso, encontramos en ambos casos la importancia de la emigración internacional como parte de la multiplicidad de estrategias campesinas, pues, "paradójicamente, es una estrategia que ayuda a no comprometer mucho el futuro de la UDPC [Unidad Doméstica de Producción Campesina] y a continuar los lazos de vinculación con el terruño entre los miembros de la familia que se quedan" (Madera, 2010: 110).

ampliar a oferta de alimentos no México, estes muitos programas possuem um orçamento inferior aos programas para acesso aos alimentos. Dados indicam que $43 \%$ do orçamento direcionado ao meio rural no México tem como destino a transferência de renda 'que incluye educación, salud y los programas de Oportunidades y Adultos Mayores' [citado del Instituto Interamericano de Cooperación para la agricultura (IICA, 2011)]. Assim, para além da fragmentação presente na política de alimentaçáo, tem existido uma centralização orçamentária em favor da dimensão acesso aos alimentos vis a vis disponibilidade, oferta e uso dos alimentos" (Souza y Belik, 2012: 116-117).

EntreDiversidades. Revista de Ciencias Sociales y Humanidades, vol. 8, núm. 1 (16), enero-junio 2021. Páginas: 119 - 140 ISSN-e: 2007-7610. https://doi.org/10.31644/ED.V8.N1.2021.A05 
Tabla 4. Amenazas a la producción campesina de alimentos en los municipios de Santiago Ixcuintla y Jala, Nayarit, y reacciones de actores locales

\begin{tabular}{|c|c|c|c|}
\hline Amenaza & Caso & Contrapesos & Acciones \\
\hline $\begin{array}{l}\text { Industria de } \\
\text { transgénicos }\end{array}$ & $\begin{array}{ll}\text { - } & \text { Monsanto } \\
\text { - } & \text { Dow AgroSciences } \\
\text { - } & \text { Pioneer }\end{array}$ & $\begin{array}{l}\text { - Amigos del maíz Jala } \\
\text { - Milpa de Cantos } \\
\text { - Jóvenes Guardianes } \\
\text { del Maíz } \\
\text { - Grupos académicos } \\
\text { UAN de } \\
\text { - Agricultura } \\
\text { "húmedo" } \\
\\
\\
\\
\text { Frente de Defensa } \\
\text { Popular Santiago } \\
\text { Ixcuintla } \\
\text { Coordinadora } \\
\text { Nacional "Plan de } \\
\text { Ayala" } \\
\text { Grupos de campesinos } \\
\text { Grupos académicos } \\
\text { UAN }\end{array}$ & 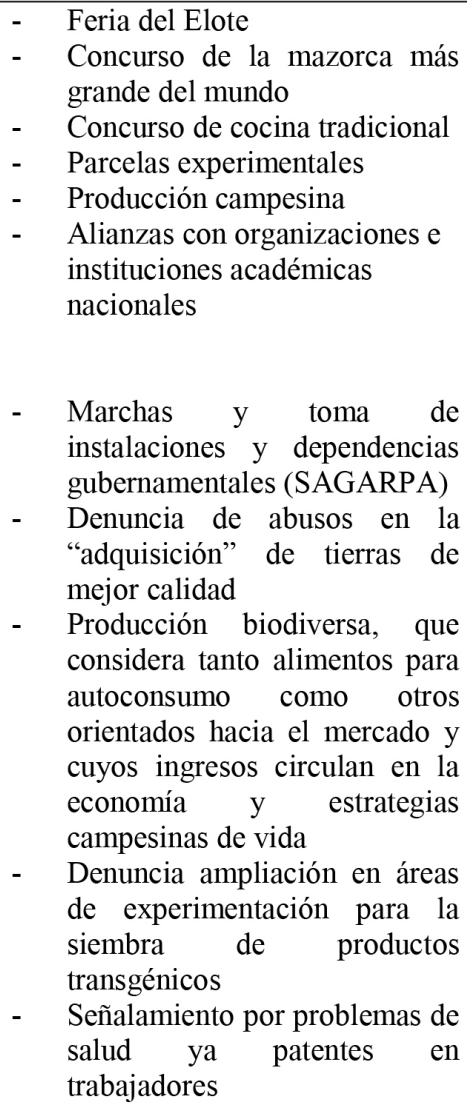 \\
\hline $\begin{array}{l}\text { Industria de la } \\
\text { energía } \\
\text { eléctrica }\end{array}$ & $\begin{array}{l}\text { Presas hidroeléctricas } \\
\text { sobre río Lerma- } \\
\text { Santiago }\end{array}$ & 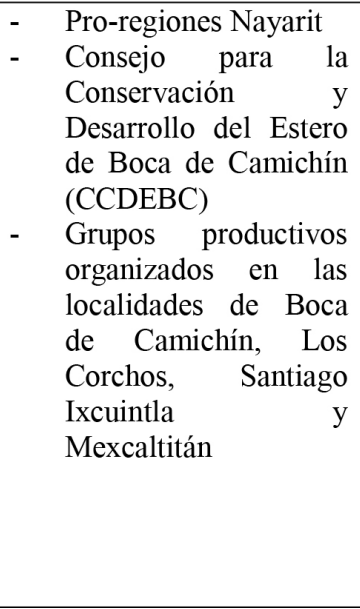 & $\begin{array}{l}\text { - Organización de la I Expo } \\
\text { Estatal del Medio Ambiente } \\
\text { "Unidos por la Madre Tierra" } \\
\text { - Proceso de acompañamiento } \\
\text { del movimiento social de } \\
\text { resistencia contra la } \\
\text { construcción de la presa Las } \\
\text { Cruces, sobre el río San Pedro } \\
\text { - Creación de equipos de } \\
\text { promotores ambientales } \\
\text { comunitarios en varias } \\
\text { localidades de la cuenca } \\
\text { Elaboración de diagnósticos } \\
\text { comunitarios participativos } \\
\text { Proyecto de Conservación y } \\
\text { Pesquería Responsable en el } \\
\text { estero Agua Larga }\end{array}$ \\
\hline
\end{tabular}

EntreDiversidades. Revista de Ciencias Sociales y Humanidades, vol. 8, núm. 1 (16), enero-junio 2021. Páginas: 119 - 140 ISSN-e: 2007-7610. https://doi.org/10.31644/ED.V8.N1.2021.A05 


\begin{tabular}{|c|c|c|c|}
\hline $\begin{array}{l}\text { Sistema } \\
\text { hidráulico } \\
\text { (trasvases y } \\
\text { acaparamiento } \\
\text { de agua) }\end{array}$ & Canal Centenario & $\begin{array}{ll}\text { - } & \text { Consejo } \\
\text { Intercomunitario del } \\
\text { Río San Pedro } \\
\text { - } \quad \text { Consejo Indígena } \\
\text { Náyeri } \\
\text { - } \quad \text { Nuiwari A.C. } \\
\text { - } \quad \text { Grupos académicos } \\
\text { UAN (CA-ASDC, } \\
\text { DCS, entre otros) } \\
\text { - Consejo Consultivo } \\
\text { para el Desarrollo } \\
\text { Sustentable, Núcleo } \\
\text { Nayarit } \\
\text { Grupo Ecológico } \\
\text { Manglar } \\
\text { Reserva Ecológica La } \\
\text { Papalota }\end{array}$ & 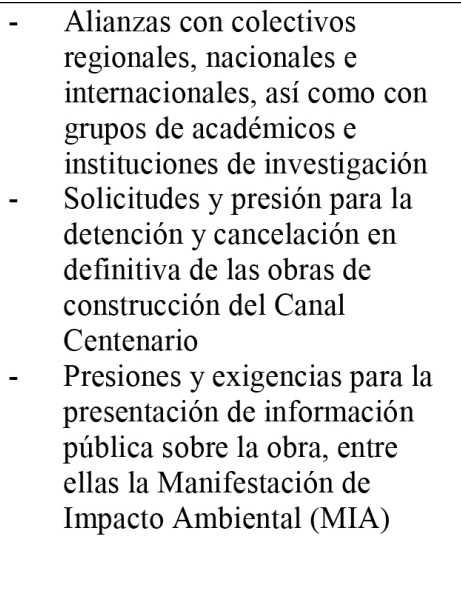 \\
\hline $\begin{array}{l}\text { Producción de } \\
\text { energía } \\
\text { geotérmica }\end{array}$ & $\begin{array}{ll}\text { - } & \text { Geotérmica para el } \\
\text { Desarrollo-Grupo } \\
\text { Dragón } \\
\text { - } \quad \text { Consorcio Mexxus } \\
\text { Drilling } \\
\text { International }\end{array}$ & $\begin{array}{l}\text { - Movimiento en } \\
\text { defensa del territorio } \\
\text { del sur de Nayarit en } \\
\text { contra de los parques } \\
\text { geotérmicos }\end{array}$ & $\begin{array}{ll}\text { - } & \text { Reuniones informativas y } \\
\text { dialogo entre municipios } \\
\text { afectados }\end{array}$ \\
\hline $\begin{array}{l}\text { Complejos } \\
\text { agroindustrial } \\
\text { es }\end{array}$ & $\begin{array}{l}\text { Horticultura } \\
\text { exportación }\end{array}$ & $\begin{array}{ll}\text { - } & \text { Amigos del maíz Jala } \\
\text { - } & \text { Milpa de Cantos } \\
\text { - } & \text { Jóvenes Guardianes } \\
\text { del Maíz } \\
\text { - } \\
\begin{array}{l}\text { Agricultura de } \\
\text { húmedo }\end{array}\end{array}$ & $\begin{array}{ll}\text { - } & \text { Feria del Elote } \\
\text { - } & \text { Concurso de la mazorca más } \\
\text { - } & \text { grande del mundo } \\
\text { - } & \text { Produrso de cocina tradicional campesina } \\
\text { - } & \text { Alianzas con organizaciones e } \\
\text { instituciones académicas } \\
\text { nacionales }\end{array}$ \\
\hline $\begin{array}{l}\text { Vacíos en } \\
\text { programas } \\
\text { institucionales }\end{array}$ & $\begin{array}{ll}\text { Granissa } & y \\
\text { reconversión } & \\
\text { productiva del tabaco }\end{array}$ & $\begin{array}{ll}\text { - } & \text { Asociación de } \\
\text { Usuarios de la Margen } \\
\text { Derecha del Río } \\
\text { Santiago } \\
\text { - } & \text { ARIC frijolera }\end{array}$ & $\begin{array}{ll}\text { - } & \text { Bloqueo de casetas y autopistas } \\
\text { - } & \text { Marchas } \\
\text { - } & \text { Acercamiento con } \\
& \text { dependencias gubernamentales }\end{array}$ \\
\hline
\end{tabular}

Fuente: elaboración propia a partir de revisión hemerográfica en Nayarit para el período 2005-2020 y Rea, 2017 
En las acciones abiertas o veladas en favor de la producción campesina de alimentos, las familias campesinas pelean también por el territorio y sus territorialidades. Las luchas se dan en el sector agroalimentario, pero también frente a intervenciones gubernamentales y sus alianzas — veladas o no- con el capital transnacional de complejos agroindustriales y/o megaproyectos con interés en esos territorios y sus recursos (Tabla 4). Frente a ellas, emergen reacciones y procesos de reconstrucción de identidades colectivas, que dan cabida a "otros actores y otras voces que, sin derechos de posesión sobre la tierra y sin estar vinculados productivamente a ellas, se pronuncian en 'defensa del territorio' y cuestionan las formas hegemónicas de territorialidad” (Paz, 2017: 216); tal es el caso, solo a manera de ejemplo, de colectivos como "Amigos del maíz Jala" o "Milpa de Cantos", así como de otras y otros actores individuales ${ }^{17}$, y sus relevantes papeles en la defensa y valorización del maíz raza Jala, en Jala, Nayarit. Al final, desde lo colectivo e individual, son actores que dan vida al territorio y que nos permiten apreciarlo en sus complejidades; como diría Paz (2017: 209), "ni aislado, ni puro, ni homogéneo".

\section{Reflexiones finales a modo de conclusión}

Las políticas públicas para la seguridad alimentaria en el caso de México, al menos desde finales de los 90 y principios de la década del 2000, han tenido características de focalización basadas en criterios de eficiencia y racionalidad económica fruto de recomendaciones del Banco Mundial y/o el Fondo Monetario Internacional. Ha habido un ir y venir de programas en cada administración gubernamental, sin embargo, el problema está ahí, cada vez más visible. En 2002, se puso en operación el Programa Estratégico de Seguridad Alimentaria (PESA) como una estrategia aparentemente diferenciada que permitiría contribuir a la transformación de las condiciones de vida en comunidades de alta y muy alta marginación; sin embargo, tanto la pobreza alimentaria como la inseguridad alimentaria y vulnerabilidad continúan creciendo pues, además, en dicha política no se consideran aspectos socioculturales de la alimentación que son diferentes en cada región/grupo social.

En este artículo, partimos de la concepción de que la seguridad y soberanía alimentarias tienen expresiones particulares y escalas diversas, por ello, reconocemos la importancia de los estudios de caso y la existencia de saberes y aportes diferenciados, pero complementarios, por género y generación entre las y los integrantes de las familias campesinas. Particularmente en los casos de estudio para el presente artículo, los movimientos de disputa en torno a la producción campesina de alimentos y, con ello, de defensa de las territorialidades construidas y resignificadas tanto en el municipio de Jala como en Santiago Ixcuintla, Nayarit, no siempre se dan en la arena pública; lo que tampoco los demerita. Velado o no, en palabras de Paz (2017: 215), "lo que se disputa a través de las luchas es su conceptualización, su valorización, su uso, su disfrute y su gobierno, lo que va ligado a formas específicas de vida que se resisten a la invisibilidad y la precarización”.

\footnotetext{
${ }^{17}$ Por ejemplo, la Chef Alondra Maldonado; Ruth Pinedo de El Itacate; el maestro Miguel González Lomelí, entre otras personas.
}

EntreDiversidades. Revista de Ciencias Sociales y Humanidades, vol. 8, núm. 1 (16), enero-junio 2021. Páginas: 119 - 140 ISSN-e: 2007-7610. https://doi.org/10.31644/ED.V8.N1.2021.A05 
Así, se presentan intervenciones que en apariencia "fortalecen" las economías regionales — por ejemplo, las documentadas en los apartados anteriores de este artículo-, pero que al final terminan por perjudicar el medio ambiente, la viabilidad de la agricultura de pequeńa escala y la seguridad y soberanía alimentaria de sus habitantes. Seguridad y soberanía alimentarias no son excluyentes (Rivera y Garrafa, 2019), sino categorías complementarias que se construyen en el día a día con, sin y a pesar del Estado, en contextos de disputa constante por la producción campesina de alimentos donde coexisten "por un lado el impulso desde el ámbito gubernamental — regional y local - al monocultivo y lo que Monsanto representa, y por otra parte, las múltiples caras de los campesinos con sus pluricultivos y pluriactividad" (Madera y Espinosa, 2018: 34).

$\mathrm{Al}$ momento de concluir la redacción de este trabajo, la Ley Federal para el Fomento y Protección del Maíz Nativo ha sido aprobada, promulgada y con entrada en vigor a partir del 14 de abril de 2020. Constituye un parteaguas en la lucha campesina e indígena por la defensa del maíz, de las territorialidades y de la soberanía alimentaria. Para Nayarit es un catalizador de las reacciones dinamizadas por los colectivos y movimientos sociales; en Jala, la citada ley ofrecerá un marco normativo e institucional para fortalecer y potencializar la defensa de la raza Jala y otros maíces criollos, por su parte, en Santiago Ixcuintla, si bien hay asociación a una variedad de maíz local, se podrían fomentar y promover la emergencia y visibilidad de actores campesinos, movimientos sociales, así como otros agentes y redes de apoyo que han sido documentados en franca lucha contra Monsanto y otras semilleras mundiales. En ese sentido, dicha ley puede contribuir a una articulación de los diferentes actores y agentes aquí presentados, ya que hasta el momento tienen presencia desde lo local/municipal y reaccionan de forma fragmentada, pero gozan de un potencial de mayor convergencia y vinculación que podría trascender hasta al ámbito de lo regional y tener con ello mayor presencia y poder de presión-acción.

Por otro lado, se valora el impulso de nuevas opciones de producción agrícola sustentable que pueden ser orientadas desde la agroecología política, pues representa una valiosa alternativa de producción de alimentos para la agricultura de pequeña escala. Estas pueden ser incentivadas por la Ley Federal para el Fomento y Protección del Maíz Nativo, por otorgar reconocimiento al maíz como patrimonio alimentario nacional desde el enfoque al derecho humano a la alimentación nutritiva, suficiente y de calidad que es obligación del Estado mexicano garantizar. Estas acciones en su conjunto comienzan a dar forma a una estructura institucional de apoyo a la producción campesina e indígena que cada vez se torna más compleja y robusta gracias a la lucha de los pueblos y comunidades campesinas.

\section{Bibliografía citada}

Consejo Nacional de Evaluación de la Política de Desarrollo Social (CONEVAL) (2020a). Medición de pobreza 2008-2018, Estados Unidos Mexicanos [en línea]. México: Gobierno de México. Disponible en: https://www.coneval.org.mx/Medicion/Paginas/PobrezaInicio.aspx (Consultado el 23 de marzo de 2020).

EntreDiversidades. Revista de Ciencias Sociales y Humanidades, vol. 8, núm. 1 (16), enero-junio 2021. Páginas: 119 - 140 ISSN-e: 2007-7610. https://doi.org/10.31644/ED.V8.N1.2021.A05 
Consejo Nacional de Evaluación de la Política de Desarrollo Social (CONEVAL) (2020b). Nayarit. Pobreza estatal 2018 [en línea]. México: Gobierno de México. Disponible en: https://www.coneval.org.mx/coordinacion/entidades/Nayarit/Paginas/Pobreza 2018.aspx (Consultado el 23 de marzo de 2020).

Crocker, René, et al. (2004). "Interculturalidad alimentario-nutricional en la etnia Wixarika de México", Revista Española de Salud Pública, (6), pp.691-700. Disponible en línea: http:// scielo.isciii.es/pdf/resp/v78n6/original3.pdf (Consultado el 12 de marzo de 2020).

De Dios, Dagoberto y Madera, Jesús (2019). "Agricultura familiar y Reconversión Productiva del Tabaco. ¿Aportaciones al cumplimiento de la Seguridad Alimentaria en México?”, en Herrera, Francisco, et al. (coords.). Vaivenes del Estado y la sociedad rural. México: Asociación Mexicana de Estudios Rurales, pp.111-130. También disponible en: http://hdl.handle. $\underline{\text { net } / 20.500 .11799 / 104544}$

De Haro, Rebeca y Marceleño, Susana (2019). "Enfoque para evaluar vulnerabilidad alimentaria aplicado a los municipios de Nayarit, México”, Estudios Sociales, 29 (53), pp. 3-24. DOI: http://dx.doi.org/10.24836/es.v29i53.695 (Consultado el 12 de marzo de 2020).

De Haro, Rebeca, et al. (2016). "La inseguridad alimentaria en el estado de Nayarit, México, y su asociación con factores socioeconómicos", Salud Publica de México (58), pp. 421-427. También disponible en: https://doi.org/10.21149/spm.v58i4.8022

Fernández-Vega, Carlos (2019). "México SA". Periódico La Jornada, [en línea]. Disponible en: https:// www.jornada.com.mx/2019/08/16/opinion/020oleco (Consultado el 14 de abril de 2020).

Gobierno Constitucional del Estado de Nayarit (2005). Plan Estatal de Desarrollo 2005-2011. [en línea]. Disponible en: https://www.bahiadebanderas.gob.mx/transparencia/6/ planesdedesarrollo/Plan\%20Estatal\%20de\%20Desarrollo\%202005-2011.pdf (Consultado el 20 de mayo de 2013).

Gobierno Constitucional del Estado de Nayarit (2011). Plan Estatal de Desarrollo 2011-2017. [en línea]. Disponible en: https://ransparencia.nayarit.gob.mx/resources/uploads/ seguridad/pdfs/Programa\%20Estatal\%20de\%20SP\%202011-2017.pdf （Consultado el 20 de mayo de 2013).

Gobierno Constitucional del Estado de Nayarit (2017). Plan Estatal de Desarrollo 2017-2021. [en línea]. Disponible en: https:/www.nayarit.gob.mx/docs/PED NAYARIT 2017-2021.pdf (Consultado el 24 de marzo de 2020).

La Jornada (2017). "Pobreza, igual que hace 25 ańos pese a que se triplicó gasto social”. Periódico La Jornada, [en línea], p. 44. Disponible en: https://www.jornada.com.mx/2017/05/17/ sociedad/044n1soc (Consultado el 13 de abril de 2020).

Long, Norman (2007). Sociología del desarrollo: una perspectiva centrada en el actor. México, D.F., México: Centro de Investigaciones y Estudios Superiores en Antropología Social / El Colegio de San Luis.

Long, Norman y Van der Ploeg, Jan Douwe (2011). "Heterogeneidade, ator e estrutura: para a reconstituição do conceito de estrutura”, en Schneider, Sergio y Marcio Gazolla (orgs.). Os atores do desenvolvimento rural: perspectivas teóricas e práticas sociais. Porto Alegre, Brasil: Editora da UFRGS, pp.21-48.

EntreDiversidades. Revista de Ciencias Sociales y Humanidades, vol. 8, núm. 1 (16), enero-junio 2021. Páginas: 119 - 140 ISSN-e: 2007-7610. https://doi.org/10.31644/ED.V8.N1.2021.A05 
Madera, Jesús (2010). “Tabaco y migración: entre la reproducción social y la sobrevivencia”, en Meza, Eduardo y Lourdes Pacheco (coords.). De aqui, de allá. Migración y desarrollo local. Nayarit, México: Universidad Autónoma de Nayarit, pp.105-120.

Madera, Jesús y Espinosa, Manuel (2018). “Crónicas de la resistencia: de cómo los subalternos trastocan las gramáticas del poder con la milpa”, en Valdiviezo, Guillermo y María Guadalupe Ocampo (coords.). Cambio socioterritorial y desarrollo local, CDMX: Colofón, pp. 33-54.

Montes, Fredy (2015). "El gasto social en México: 2008-2015 (I)”. El Economista, [en línea]. Disponible en: https://www.eleconomista.com.mx/opinion/El-gasto-social-en-Mexico2008-2015-I-20150629-0007.html (Consultado el 13 de abril de 2020).

Navarro, Myriam (2018). "Productores de frijol toman caseta en Nayarit por falta de apoyo económico". Periódico La Jornada, [en línea]. Disponible en: https://www.jornada.com. $\mathrm{mx} /$ ultimas/estados/2018/04/02/productores-de-frijol-toman-caseta-en-nayarit-porfalta-de-apoyo-economico-5410.html (Consultado el 12 de abril de 2020).

Nieves, Francisco (2018). "Desaparece la NASA, pero llega DIVEMEX, con ofertas de trabajo". El Regional del Sur, [en línea]. Disponible en: https://www.regionaldelsur.com/desaparecela-nasa-pero-llega-divemex-con-ofertas-de-trabajo/ (Consultado el 18 de marzo de 2020).

Núñez, E. (2010). "Así avanza Nayarit... Ney González lleva el desarrollo económico a Jala”. NNC, [en línea]. Disponible en: http:/www.nnc.mx/categoria/Nayarit/ney-gonzalezlleva-el-desarrollo-economico-a-jala/31472 (Consultado el día 17 de marzo de 2020).

Paz, María Fernanda (2017). "Luchas en defensa del territorio. Reflexiones desde los conflictos socio ambientales en México”. Acta Sociológica, (73), pp. 197-219. También disponible en: http://dx.doi.org/10.1016/j.acso.2017.08.007

Presidencia de la República EPN (2013). ¿Sabes qué es Diconsa? [en línea]. Disponible en: http://www.diconsa.gob.mx/index.php/conoce-diconsa/ique-es-diconsa.html (Consultado el 18 marzo de 2020).

Rea, Carlos (2017). "Convergencia y conflicto social en la cuenca del río San Pedro: el proyecto Pro-Regiones Nayarit (2006-2012)", en Martínez, José Luis, et al. (coords.). Conflictos por el agua y alternativas en los territorios indígenas de México. Jiutepec, Morelos, México: Instituto Mexicano de Tecnología del Agua, pp. 211-236. También disponible en: https://agua.org.mx/wp-content/uploads/2017/12/conflictos-por-el-agua-y-alternativasen-territorios-indigenas-en-mexico.pdf

Rivera, Karla y Garrafa, Olivia María (2019). "Estrategias de seguridad y soberanía alimentaria en localidades agropecuarias de Ruiz, Nayarit”, en Herrera, Francisco, et al. (coords.). Vaivenes del Estado y la sociedad rural. México: Asociación Mexicana de Estudios Rurales, pp. 89-110. También disponible en: http://hdl.handle.net/20.500.11799/104544

Servicio de Información Agroalimentaria y Pesquera (SIAP) (2019a). Nayarit: Infografía Agroalimentaria 2019. Ciudad de México: Gobierno de México.

Servicio de Información Agroalimentaria y Pesquera (SIAP) (2019b) Panorama Agroalimentario 2019. Ciudad de México: Gobierno de México.

EntreDiversidades. Revista de Ciencias Sociales y Humanidades, vol. 8, núm. 1 (16), enero-junio 2021. Páginas: 119 - 140 ISSN-e: 2007-7610. https://doi.org/10.31644/ED.V8.N1.2021.A05 
Sifuentes, Emma y Rivera, Karla (2013). "Redes, agencia social y organización laboral en los invernaderos de tomate del Sur de Nayarit, México”, en Madera, Jesús, et al. (coords.). Actores rurales frente al modelo de desarrollo neoliberal. Tepic: Universidad Autónoma de Nayarit, pp. 59-72.

Souza, Luciana Rosa de y Belik, Walter (2012). "O planejamento da política de alimentação: uma análise a partir dos casos do México, Brasil e Perú”, Segurança Alimentar E Nutricional, 19 (2), pp. 111-129. DOI: https://doi.org/10.20396/san.v19i2.8634615 (Consultado el 12 de marzo de 2020).

Torres, Fredyd, et al., (2015). "Etnografía institucional del proyecto estratégico de seguridad alimentaria (PESA) en una comunidad mazahua”. Nueva Antropología, 28 (82), pp. 5181. También disponible en: https://revistas-colaboracion.juridicas.unam.mx/index.php/ nueva-antropologia/article/view/15348/13689

Ulloa, Fernando (2009). "Nayarit será la capital mexicana de la producción en invernaderos". News Network Communication nnc.mx, [en línea]. Disponible en: https://www. nnc.mx/categoria/nayarit/ nayarit-ser -la-capital-mexicana-de-la-producci_n-eninvernaderos :-ney/21548 (Consultado el 29 de diciembre de 2020).

Universidad de Guadalajara (2015). México ha perdido la soberanía y seguridad alimentaria: Gerritsen [en línea]. Disponible en: http://www.cusur.udg.mx/es/noticia/mexico-ha-perdido-lasoberania-y-seguridad-alimentaria-gerritsen (Consultado el 20 de agosto de 2018).

EntreDiversidades. Revista de Ciencias Sociales y Humanidades, vol. 8, núm. 1 (16), enero-junio 2021. Páginas: 119 - 140 ISSN-e: 2007-7610. https://doi.org/10.31644/ED.V8.N1.2021.A05 